\title{
The Appliance of Gender Analysis Model Sara H. Longwee Study on the Problem of Female Lecturer in Functional Position in High Education
}

\author{
${ }^{1}$ Widyatmike Gede Mulawarman, ${ }^{2}$ Abdullah Karim \\ ${ }^{1}$ Faculty of Teacher Training and Education, Mulawarman University, East Kalimantan, Indonesia \\ ${ }^{2}$ Faculty of Social and Political Sciences, Mulawarman University, East Kalimantan, Indonesia \\ widyatmikegedemulawarman@yahoo.co.id ${ }^{1}$, akarimfisip@yahoo.com ${ }^{2}$
}

\begin{abstract}
This paper considers the issue of women who position themselves as career women in a functional position as one of the conditions of structural positions in college. Speaking of structural positions always involves relationships between men and women manifested in various forms and patterns of behavior that reflect male or female acceptance of the position of each sex. This process is reinforced by the reality in many cultures that the position of men is higher structurally than women. This proves that the interaction exists demands the existence of one gender superior to the other. The male side is a winner, has greater power and a more decisive role in various social processes than women, even in the wider social sphere of society. The decisionmaking process in a family, is inseparable from the control of men's power that is considered more authorized. When discussing women's issues, one important concept that should not be forgotten is the gender concept. This is a crucial issue because the stereotype formed by gender in its application has a tendency to favor certain sexes that is male. These advantages appear in various forms of social and cultural order that apply to people who embrace patriarchal culture. Women are depicted with certain images that impress women's inferiority, both in social structures as in structural positions in college.
\end{abstract}

Keywords - Inhibiting factors; career of female lecturers; functional position

\section{INTRODUCTION}

In the general sense, the study of female lecturers referred to all studies which concerned to female lecturers. For example, the study of women's history to obtain / position themselves as career women in the functional positions in universities so that the relationship between men and women could be manifested in various behavioral forms and patterns which reflected the men and women's acceptance toward each position[1]. This process was strengthened by the fact that in many cultures, the men position was higher structurally than women. This proved that the existing interaction demanded one of them to be superior to the other[2]. The men side was the winner, which had greater power and a more decisive role in various social process than women, and even in the wider society such as community groups. The decision-making process in a family was inseparable from the men's control which was considered to be more authoritative.

Throughout the past decade, since the issuance of Presidential Instruction No. 9 of 2000 on Gender Mainstreaming (PUG) in human development, the issue of women's involvement in all aspects of life is still marginalized. In this study, researchers focused on the elements of educators (lecturers) as the perpetrator and one type of profession that is directly related to the education process in college. As stated in the Law of the Republic of Indonesia Number 14 Year 2005 on Teachers and Lecturers, it is mentioned that "lecturers are professional educators and scientists with the primary task of transforming, developing and disseminating science, technology and art through education, research and devotion to society.

This condition occurred and seemed to be legalized by the construction of local culture. This process was repeated many times that it shaped a negative view about women which also included their functions, roles, and position in social life[3]. One of them was a stereotype saying that women were weak, while men were strong. Based on this, women had a strong tendency to depend on men. Instead, men had an authority to control women in many ways.

In discussing women's issues, one important concept that should not be forgotten was the gender concept. This was a crucial problem regarding the stereotype formed by the gender and its application which had a tendency to favor a certain sex, which was male. Those advantages appeared in many social and cultural order which applied to the society who embraced patriarchal culture[4]. Women were depicted in certain images which created the women inferiority, like in social structure such as in structural position in universities.

A close look at the women issues in pursuing careers in university could be observed by looking at women in the following quantitative data. Globally, based on the Central Bureau of Statistics data, the amount of productive people whose age ranged between 40-45 years in East Kalimantan Province in 2015 were 17.253 men and 18.448 women[5]. This indicated that most of them were women and that made it a 
basis for positioning women as an important part of human resources. The number of these women reinforced the argument about the importance to think and find solutions for problems and These problems are further detailed more specifically in the questions we wanted to answer, particularly with regard to: in pursuing functional position for female lecturers became the reason for the researcher to make this as the object of the research. As stated earlier in the introduction, the problems emerged were formulated into this following question, 'How is the female lecturers' career's achievement, participation and representation in pursuing career in functional position?" (1) How is the issues of women lecturers in career functional position; (2) Internal factors that hinder the achievement, participation and representation of women in lecturers careers of functional position; (3)External factors that hinder achievement, participation and representation of women in lecturers careers of functional position.

\section{LITERATURE REVIEW}

\section{A. Ideology of Gender and Career Development}

The history of the development of the life of women in employment through different socialization process against the introduction of labor between men and women. The socialization process of division of labor seen in boys and girls in the family that continues in the community (culture)[6].

The development of gender ideology on society then creates the gender roles of men and women who are oppositional [7]. In the division of gender roles of a girl is always directed at roles that are domestic, reproductive, feminine, and if women work rather than as the main breadwinner, but when the boys were directed at the roles that are productive, the public, masculine, and the main breadwinner, while women are only as a secondary earner.

In some literature described that women as a group are more concentrated in lower status jobs, low salaries, and are not taken into account or not considered as work profession. Women have always been associated as a housewife watchman home, children and husband[8]. Or more specifically, women are socialized mainly for working household or household roles or roles that are considered secondary (second priorities).

The women work outside the home, then the work intended for women are always associated with the household, which has a characteristic not require complex thinking and the kind of work that demands practical skills for example as a teacher, secretary, nurse [9].

There is a difference between the process of career planning of women and men that takes into account differences in perspective between men and women. Women in job or career plan based on the consideration associated with family and career. This means that women in completing the tasks are always inseparable from the role of domestic-reproductive causing many women lose job opportunities to pursue professional duties. Unlike the men in planning for a career based on the roles that are independent (free) is not bound by anything, so men can freely develop his career.

\section{B. Patriarchal Decisions in Organizational Culture}

Robbins (1990) says that the bureaucracy often lead to concentration of power in a few people [10]. As a result, if a decision will not reflect the interests of all employees, including women as a minority group. It is even possible to prevent deviation of the organization, from the organization's goals into personal goals. If we reflect on the data before opening insights, the concentration of power that exist in men who make up the majority in the organizational structure.

\section{Women and leadership}

All humans (male and female) have a number of potential, one of them becomes the leader[11]. But because of the traditional gender bias as men play the main breadwinner, while women as secondary wage earner the share leadership always held by men. Similarly, the influence of culture on formal education, because the main breadwinner man then more men be counted in education.

\section{RESEARCH METHOD}

The focus of the study with regard to the issue of female lecturers in functional positions in universities addresses problems of female lecturers in positioning itself as an educator in a functional position. Setting research was in Samarinda .The determination of the Samarinda as the research setting to the consideration of Samarinda as the provincial capital is a city that has public universities and is a transit city that has pretty much college facilities.

This research was done in qualitative-descriptive manner which relied on social behavior data in the form of the lecturers' condition in universities in Samarinda. The data collection technique used in this research was purposive sampling and snowball method[12], [13]. It was expected that the researcher would get female lecturers who were sufficient and satisfying as the key informants and had experience in Tri Dharma Perguruan Tinggi and had accomplished their S3. Regarding the need of providing the data, the information was obtained through several informants which were (1) Lecturers who had become a professor and occupied a strategic position in university, lecturers who had not become a professor yet had accomplished their S3 and had met the requirements to be promoted as the professor, and lecturers with more than 20 years of work experience and had become the head lector. In collecting the data, the techniques used were various, such as (1) In-depth interview (interview guide), (2) observation, used to elicit cases related to the lecturer's career which were hampered due to the prevailing regulation and (3) focus group discussion. After selecting the data, then it was discussed to decide which one was the essential to be used as the material to be analyzed.

In addition to interactive analysis, gender analysis of Sara H. Longwee's “Women's Empowerment Framework" model which was based on the importance of development for women was also used [14]. The women empowerment included three points: (1) capacity building which referred to build woman's ability; (2) cultural change which referred to cultural changes which favored women; (3) structural adjustment which referred to the structural adjustment which favored women. The 
empowerment efforts were directed to achieve the society's welfare through gender equality. The analysis criteria used in this method consisted of 5 (five) criteria: (1) welfare; (2) access; (3) awareness: (4) participation; and (5) control.

\section{RESUlT AND DISCUSSION}

In this discussion shelled female lecturers problems when applying file promotion fungsional.Hala especially in positions that affect the careers of functional positions are classified into three categories of lecturers, namely: (a) Type of female lecturers with all the problems of women who have the achievements of female lecturers in Tri Dharma College smoothly so that the position of highest functional post as a professor is reached, (b) type of female lecturers with the issue of female lecturers successfully study S3 with functional Lector head, (c) type of female lecturers with the issue of female lecturers have not S3, already on the position of lector head

Overview issue of female lecturers in functional positions include all related elements in the overall internal factors may be an inhibiting factor and a contributing factor in career functional positions in college: Limitations of female teachers in using information technology generally experienced by female lecturers aged over 50 years. (A) Type of female lecturers with all the problems of women who have the achievements of female lecturers in the Tri Dharma College smoothly so that the position of highest functional post as a professor is reached, (b) Type of female lecturers with the issue of female lecturers successfully study S3 with functional positions Lector head, (c) type of female lecturers with the issue of female lecturers S3 yet, is already in the position of lector head

Ignorance about the status of female lecturers' reputable journals national / international and Scopus indexing. The opportunity to write a proposal competitively is also an obstacle for female lecturers, because the busy teaching and obsolescence in the technology field and the difficulty of being accessed by female lecturers causes the female lecturers less motivated to write proposals, conducting research especially for lecturers of the senior lecturers category (category above 50). And the existence of rules of research results should be published to the national / international journal that is reputable to cause the position of female lecturers increasingly lagging behind. Only certain female lecturers, such as young lecturers, are supported by the level of education, and the advantage of mastering English as a reference to understand the prevailing system. Thus, this scholarly publication is also a benchmark for lecturers' not only female lecturers but also male lecturers. Here are the key informant statements that support the classification of the first female lecturer "The obstacles I experienced in proposing functional positions are some of them are the targets achieved at least group IVa in order to reach the retirement age of 65 . The reason is why the target is only up to the head lector because as a women are not the primary breadwinners and therefore consider their income only to support the obligation of the husband as the head of the family who is supposedly responsible for meeting the needs of the whole family. He also thinks that as a woman when she is 65 she is not able to move optimally.
He also has no hope to achieve professorship because at that time around the 90 s there has been no government policy that provides benefits to lecturers who managed to reach the professor. In other words, there is no government attention to the profession of lecturers who have professorship. He also deplored himself why he did not try as optimally as possible to reach the professor when at that time the requirement to reach the professor has not been as heavy now. It is said why it is not strived now, he said it is impossible because at this time to reach the professors have to study S3. To go to the S3 he said he did not have financial support because of the high cost of education while his income as a lecturer who has class IVa with 3 children does not allow to cover the cost of education is quite expensive. Expecting a scholarship is also impossible due to age limit.

There are rules that impose penalties in the form of cuts in benefits when lecturers should collect data outside the area and follow activities outside the area. The involvement of female lecturers in research and dedication is very limited. This condition is caused by the problems faced by female lecturers enough to interfere with their activities as lecturers and as housewives so that the opportunity to write proposals, research reports and submit articles to the national and international journals that Scopus indexing experiencing various constraints, one of which is the ability to use low technology. Here is the statement of one of the key informants: Until now I have not proposed a group increase because I just came to study postgraduate studies from outside the region. When I suggested my rank was blocked by the new rules. I have not been able to propose a group increase since I have to wait a year after completing my studies. After compiling and collecting the file the credit score points are still not fulfilled all of which is a report of research and dedication. Until now I have not had time to write research and devotion because of the many teaching tasks every day. The number of classes I face causes a lack of time to write.

In addition to these problems the problem of children also make their own constraints in dividing the time to write at home because my son who is still very toddler seized my attention at home. If I have a helper the possibility of a child's problem can be resolved but my income is not sufficient to pay a maid who stipulates $1,500,000$ per month of Indonesian Rupiah. As a lecturer whose position is still an expert assistant is certainly far from enough especially if the child suffers from illness. Not only the financial needs are bloated but the attention must also be extra so that in itself the teaching tasks are also disrupted.

In addition to these problems that I feel is a severe financial problem because all activities stem from financial problems both related to the family and in supporting the career of lecturers. This I feel when to meet the tri dharma support points of college must have a certificate, while to obtain the certificate must follow the activities generally carried out outside the region, here of course must prepare the cost of accommodation, transportation, registration etc. that all I feel as obstacles in improving his career.

The scarcity of the journal and the high cost of entering the article I felt as a burden that I was pessimistic to write a 
scientific paper. What else is required to choose a journal that is reputable nassional / international as well as indexed scopus even less enthusiastic to write because of the tight competition. I really hope that the government change the wisdom that I feel is very heavy and maybe other lecturers also feel the same.

There are rules that limit the nomination of the rank of at least one year after completing the graduate program. The issue of accessing national / international journals is the main issue of female lecturers, along with the lecturer's statement in the focus of discussion

I actually already have the requirements to propose functional positions to the professors. According to my rough calculation credit points have reached 1000 but I am not sure with my own calculation results because I do not have knowledge of reputable national / international journals and Scopus indexed. Some of my research has also been entered into international journals which at that time I spent until millions of dollars but the obstacles I do not know the status of the journal. When touched on his experience in conducting research, he did not feel the difficulties that meant only a matter of time that had been felt very short because to get credit points that much I have to attend international seminars both held abroad and domestically. As a result of that all I so much left my teaching hours. This I feel dilemma because on the one hand I have to impose tri dharma duties of universities outside Campus on the other hand I also have to fulfill obligations in the field of teaching. During the FGD an interactive dialogue took place among some participants. Some FGD participants asked how their tricks in conducting research, seminars, dedication to be able to collecting credit points to the professor whether the cost so far is not an obstacle as experienced by some female lecturers who are relatively young age. It turns out that during this financial problem is not a constraint because by doing research it can supplement its income. Only it should be able to establish cooperation with various parties and every time should be ready proposal in hand. To fulfill my wish I did sacrifice my sleep time which an average of 4 hours in one day.

There are rules that restrict the research theme should be the same as the name of the courses listed in the Decree of Functional post

Financial Limitations female lecturers as a single parent when it must pay research, seminars, community service, the cost of entering scientific articles into a journal that is indexed Scopus reputed and national / international.

Problems household mainly on female lecturers who still have children under five.

A very significant female issue is a family problem for working women. In addition to household affairs, according to the nature of pregnant women and childbearing. Then the working woman will take care and educate the child. This condition can be a barrier for women when not supported by their partner, material support and so forth. Unlike the male lecturers can have a career without barriers because all the homework and children are already there who take care. Usually for female lecturers who just started his career rather difficult to choose a career or family, so was forced to wait for his big son first develop new career.

The number of teaching hours that are charged to lectures so did not have time to do research. Still found female lecturers who because of additional tasks, for example as the head of study and teaching duties are very solid so forget the duties of Tri Dharma other universities such as doing research and community service. This condition causes female lecturers to lag behind in the promotion.

Limited understanding lecturer in calculating the credit rate. There are still many female lecturers who cannot calculate the number of credit in proposing promotion. This condition is caused by the calculation of credit score and not the duty of the lecturer but should already be part of the duty of the personnel department. Due to ignorance in calculating the performance of lecturers and there is no good cooperation between lecturers and staffing department, the calculation of credit number when promotion becomes one of the obstacles for female lecturer for functional position .

Internal factors which support the career development of female lecturers in a functional position are education, employment, activity and motivation of female lecturers in the Tri Dharma College makes female lecturers in the functional position, but the main capital is not / underutilized female lecturers to immediately achieve the highest functional post at University. This condition is supported by low aspirations and motivation of female lecturers because it has been involved in the work of domestic realm that female teachers tend to quickly satisfied with the condition that has been achieved today. When achievement and involvement of female lecturers in the Tri Dharma College used carefully due to the support of children and husbands: (a) In general, children have a sense of pleasure and pride to have a mother who works as a lecturer. The attitude of other children as a form of child support to the mother is willing to be left at home while the mother was out of town duty. Children also want to help some homework for mothers on duty outside the house. These forms of support are greatly needed by the lecturer women because it can be a positive influence for the improvement of performance as a lecturer. Females working outside the house certainly play double roles, i.e. performing public work on one side and being demanded to perform domestic works (hence causing a very great work load). This condition greatly affects the career development of females, however if these double roles are addressed positively (in the sense that the working females receive full support from family), the objectives of working females such as actualizing oneself (23.33\%), increasing perception $(51.33 \%)$ and fulfilling family needs $(25.33 \%)$ no more serve as inhibiting factors for the career of females, instead they may become motivation in developing the career of females as lecturer.

If the respondents' answers or comments are studied carefully, the choice of working outside the house (public sector) is very good in the sense it is highly supporting for serving as stimulating factor to increase achievement to a higher level, i.e. holding the highest position in higher education as the principal. However in reality, the opportunity is not used enough, and even less demanded by female lecture 
for the reason that they are satisfied with the double works and roles carried so that they become a very big work load and females are not motivated to increase their career.

A woman working in public sector certainly needs the family's full support (husband and children), because if a woman works without the family's support, this internal factor will become an inhibiting factor for the woman's career development. If studied carefully, the support given by the husband will be the main asset to promote or develop the achievement of female lecturer one level higher. The support given by the husband can be specified as follows, usband support is very important when female lecturers decide to occupy strategic positions in faculty such as deans, vice deans or department directors. Of the fourteen faculties there are only three female deans, whereas the support of husbands is very high and becomes a motivation for female lecturers, but the opportunity is not used maximally, on the grounds that workload will increase or there are female lecturers who always think about something excessively.

External factors are factors that influence from the outside, the study covers (a) even if the rules governing the process of proposing the increase of functional positions does not distinguish between male professors and female professors, but the responses given between female lecturers and professors of different men. This is because the burden of the task that more women are having to engage in domestic realm this could be a limiting factor when female teachers can not manage the well, (b) Surrounding communities, people's views about the women who work outside the home still sound, this condition can be a limiting factor when female lecturers then stop an activity (demands Tri Dharma PT) are not met. In addition, the limiting factor when generally respond positively to women who work as teachers so are not required to carry out civic duties if it is not possible because of busy work. (C) The working environment does not distinguish lecturers men and women because in carrying out the task more priority fields skills of teaching courses without gender. Support the work environment on women seen from the good cooperation among lecturers and between lecturers and study program coordinator. Thus the work environment has not the potential to hinder women in developing his career

\section{CONCLUSION}

The result of this research indicated 3 categories of female lecturers: (a) A type of female lecturers who despite of all women's problem who had female lecturers' achievement in Tri Dharma Perguruan Tinggi, kept going well so that the highest structural position as a professor was achieved, (b) A type of female lecturers with all female lecturers' problems who managed to accomplished her S3 with functional position as the head lector, (c) A type of female lecturers with all female lecturers' problems who had not accomplished her S3, but managed to be the head lector position. Those classification of those three categories could not be separated from the women's problem which could inhibit their achievement in functional position. The elements that inhibited the female lecturers' career included internal and external factors. Overview issue of female lecturers in the functional position, is covering all related elements in the overall internal factors may be inhibiting factors and supporting factors in pursuing a career in the functional positions in college:

1. Internal factors that support the career development of female lecturers in a functional position are education, employment, activity and motivation of female teachers in the Tri Dharma College makes female lecturers in functional positions, but the main capital is underutilized female lecturers to immediately reach the office highest functional in college. This condition is supported by low aspirations and motivation of female lecturers because it has been involved in the work of domestic realm that female lecturers tend to quickly satisfied with the condition that has been achieved today. When achievement and involvement of female lecturers in the Tri Dharma College used carefully due to the support of children and husbands: (a) In general, children have a sense of pleasure and pride to have a mother who works as a lecturer. The attitude of other children as a form of child support to the mother is willing to be left at home while the mother was out of town duty. Children also want to help some homework for mothers on duty outside the house. These forms of support are greatly needed by the female lecturer because it can be a positive influence for the improvement of performance as a lecturer.

2. External factors are factors that influence from the outside, the study covers (1) even if the rules governing the process of proposing the increase of functional positions does not distinguish between male lecturers and female lecturers, but the responses given between female lecturers and male lecturers of different. This is because the burden of the task that more women are having to engage in domestic realm this could be a limiting factor when female lecturers cannot manage well, (2) Communities around, people's views about the women who work outside the home still sound, this condition can be a limiting factor when female lecturers then stop an activity (demands Tri Dharma PT) are not fulfilled. In addition, the limiting factor when generally respond positively to women who work as lecturer so are not required to carry out civic duties if it is not possible because of busy work. (3) The working environment does not distinguish lecturer's men and women because in carrying out the task more priority field's skills of teaching courses without gender. Supporting the work environment on women seen from the good cooperation among lecturers and between lecturers and study program coordinator. Thus the work environment has the potential to hinder women in developing his career.

\section{REFERENCES}

[1] S. Winocur, L. G. Schoen, and A. H. Sirowatka, "Perceptions of Male and Female Academics Within a Teaching Context.," Res. High. Educ., vol. 30, no. 317-329, 1989.

[2] A. Edgar and P. Sedgwick, Key Concepts in Cultural Theory. London and New York: Routledge, 2005.

[3] M. E. Heilman, "Description and Prescription: How Gender Stereotypes Prevent Women's aAscent Up The Organizational Ladder.," J. Soc. Issues, vol. 57, no. 4, pp. 657-674, 2001.

[4] A. B. Diekman and A. H. Eagly, "Stereotypes as Dynamic Constructs: Women and Men of The Past, Present, and Future.," Personal. Soc. Psychol. Bull., vol. 26, no. 10, pp. 1171-1188, 2000. 
[5] B. P. Statistik, "BPS-Statistics Indonesia." 2015.

[6] R. M. Kanter, Men and women of the corporation: New edition. Basic books, 2008.

[7] R. Saptari and B. Holzner, Working Women and Social Changes. Jakarta, 1997.

[8] A. Iyer and M. K. Ryan, "Why do Men and Women Challenge ender Discrimination in The Workplace? The Role of Group Status and in-group Identification in Predicting Ppathways to Collective Action," $J$. Soc. Issues, vol. 65, no. 4, pp. 791-814, 2009.

[9] D. Brown, Career Choice and Development. John Wiley \& Sons, 2002.
[10] S. P. Robbins, Organization Theory: Structures, Designs, And Applications, 3/e. Pearson Education India, 1990.

[11] Momsen and J. Henshall, Women and Development in Third World. London and New York: Routlegde, 1991.

[12] N. K. Denzin and Y. S. Lincoln, Handbook of Qualitative Research. Thousand Oaks, London and New Delhi. Sage Publications, 1994.

[13] J. W. Creswell, Research design: Qualitative, quantitative, and mixed methods approaches. Sage publication, 2013.

[14] S. Mosedale, “Assessing women's empowerment: Towards a conceptual framework," J. Int. Dev., vol. 17, no. 2, pp. 243-257, 2005. 